\title{
Assessment of Clinical Reasoning and Diagnostic Thinking Among Dental Students
}

Fatemeh Keshmiri ( $\nabla$ keshmiri1395@gmail.com )

Shahid Sadoughi University of Medical Sciences and Health Services

\section{Fatemeh Owlia}

Shahid Sadoughi University of Medical Sciences and Health Services

\section{Maryam Kazemipoor}

Shahid Sadoughi University of Medical Sciences and Health Services

\section{Fahimeh Rashidi Meybodi}

Shahid Sadoughi University of Medical Sciences and Health Services

\section{Research Article}

Keywords: Clinical reasoning, Diagnostic thinking inventory, student, medical education, curriculum

Posted Date: August 20th, 2021

DOl: https://doi.org/10.21203/rs.3.rs-792901/v1

License: @ (i) This work is licensed under a Creative Commons Attribution 4.0 International License. Read Full License 


\section{Abstract}

\section{Aim and background:}

Diagnostic thinking is the ultimate goal of educational system and the basis for clinical reasoning. The aim of this study was to assess the clinical reasoning and diagnostic thinking ability of dental students by key features test and Diagnostic thinking inventory (DTI) questionnaire.

\section{Materials and methods}

The present study was a descriptive cross-sectional study. The participants consisted of 61 senior dental students. Clinical reasoning and diagnostic thinking were assessed by key feature test and DTI questionnaire, respectively. To design the KF test questions, the blueprint of exam was first designed in expert panel based on dental curriculum. The questions developed based on common cases in oral and maxillofacial diseases by the group of oral and maxillofacial specialists. The DTI was developed by Bourdieu et al. in France and consists of 41 questions on a 6-point Likert scale, of which 21 are memory structure category and 20 are in flexibility in thinking category. Satisfaction of student assessed through a 10-item questionnaire. Data were analyzed using SPSS 19 by descriptive tests (mean, SD, percentage) and student independent T-test and Pearson test. Significance level was determined $p<0.05$.

\section{Results}

The mean scores of the key features test of students were $56.55 \pm 7.80$. No significant difference was reported between clinical reasoning scores of key features test by students' gender ( $p$-value $=0.19)$. There was no significant difference between the scores of diagnostic thinking between men and women ( $\mathrm{p}$ value $=0.11$. The difference in students' scores in the domain of flexibility in thinking was significantly higher among male students than female students. (P-value $=0.04)$. There was no significant correlation between students' diagnostic thinking scores and their clinical reasoning scores in the key features test.

\section{Conclusion}

Based on the present results, the clinical reasoning and diagnostic thinking skills of participants were reported in the low level. This issue emphasizes the need for training to enhance diagnostic thinking and clinical reasoning in dental education. Formative evaluation and reform the educational programs of this course should be considered.

\section{Introduction}

Clinical reasoning is considered as one of the most important skills required for health personnel $(1,2)$. Clinical reasoning is a logical thinking process that guides the health providers to take purposeful steps 
in diagnosis and treatment. This process exists in all stages of dealing with the patient, from the initial stage of getting the history of the disease to the patient management and follow-up(3). Having clinical reasoning as a clinical competency is considered essential and has been introduced as one of the essential skills for conducting professional responsibility and responding to patients(4).Clinical reasoning consists of four components; data collection, clinical hypothesis formation, hypothesis testing, clinical decision making and problem-solving. Educational methods such as problem-based learning, team-based learning and cases based learning are recommended to develop the reasoning skills of medical students(5). Insufficient attention to teaching clinical reasoning skills and related concepts increases the miss diagnosis as the main cause of medical errors (6). Therefore, teaching clinical reasoning to students of medical sciences is important $(7,8)$. The majority of medical graduates do not achieve the correct clinical reasoning skills to diagnose and perform effective and safe interventions for patients $(7,9,10)$. This topic highlights the importance of teaching critical thinking skills and clinical reasoning.

The goal of educational systems is to switch the memorization approach to the development of learners' reasoning skills and problem-solving ability (11). Clinical reasoning training actually provides students with the opportunity to achieve critical thinking, clinical decision-making, and learning in three areas of cognitive, affective, and psychomotor to prepare them for their professional role in society (12). In the dentistry, the decision-making and reasoning skills have vital role in the field of oral and maxillofacial medicine. The main activities of this field are the ability to diagnose and treat oral mucosal lesions, salivary gland diseases, and temporomandibular joint and dental management of patients with systemic diseases. Early ddiagnosis of oral lesions is important because many of them could be the first sign of undiagnosed systemic disease or lead to a malignant lesion with late diagnosis of a pre-malignant lesion. Currently, the dentistry curriculum mainly focuses on the development of procedural skills. Although, there is a need to change the training processes and evaluate clinical reasoning skills in school of dentistry.

The improvement of clinical reasoning among learners needs to consider in teaching and assessment process in clinical education $(10,13)$.

The Key-Feature (KF) test is introduced a subset of clinical reasoning tests. KF is a scenario-based clinical exam that solves the clinical problem through a number of questions about important actions or clinical decisions $(13,14)$. In this test, a short scenario with little information is provided to the examiner and he/she detect key information by selecting the choices. The value of responding to different options in the KF test varies and could be changed according to their values in patient's diagnosis and treatment. In $\mathrm{KF}$ test is assuming not all information is of equal value, but there are key points that are more important in solving the problem than other symptoms. A mistake in identifying them will cause the failure to solve the problem correctly. This test mainly focuses on more valuable points of diagnosis and treatment rather than others. 
The advantages of this test include the ability to evaluate clinical decision-making, the possibility of wider coverage of clinical cases compared to other reasoning tests, the design of various forms of answers. High reliability and the possibility of more structured and focused evaluation of clinical cases introduced as the benefits of the test (15). According to studies, the KF test is a suitable test for measuring clinical reasoning skills of medical students and its score is closer to the OSCE test scores (16, 17).

Other tools were introduced to assess clinical reasoning skills. One of them is Diagnostic Thinking Inventory (DTI) (18). DTI is a tool that measures the flexibility in thinking and structure of knowledge in memory independently of content and can evaluate different degrees of medical skills(19). DTI is a suitable tool for comparative assessment of clinical reasoning ability based on their self-expression among students with different curricula. Diagnostic thinking is different from critical thinking and both are used to assess clinical reasoning (20-22). Groves et al. noted that this questionnaire is directly related to the clinical reasoning process of examinees (20). Hamzeh et al. compared clinical competency using diagnostic thinking in experienced and inexperienced physiotherapists. Their results showed that the DTI instrument had sufficient validity and reliability to assess clinical diagnostic reasoning (23).There were founded a few studies about assessing clinical reasoning and diagnostically thinking among dental students. The aim of this study was to assess the clinical reasoning and diagnostic thinking abilities of dental students through key features test and DTI questionnaire.

\section{Method}

The present study was a descriptive cross-sectional study.

\section{Participants}

The study population consisted of 61 students of the 11th semester in X dental schools who were chosen based on census method.

To design the KF test questions, the blueprint of exam was first designed in expert panel based on dental curriculum. Based on the studies (17), to achieve the desired reliability in this process, 17 questions were designed and reviewed after design (Tables 1 and 2). The questions developed based on common cases in oral and maxillofacial diseases by the group of oral and maxillofacial specialists. 
Table 1

Blueprint of key-features exam

\begin{tabular}{|llcccc|}
\hline Subject area & $\begin{array}{l}\text { First } \\
\text { assessment }\end{array}$ & diagnosis & $\begin{array}{l}\text { Laboratory } \\
\text { tests }\end{array}$ & $\begin{array}{l}\text { Dental } \\
\text { management }\end{array}$ & $\begin{array}{l}\text { \% of } \\
\text { exam }\end{array}$ \\
\hline convulsion & & & 1 & 5.8 \\
\hline Endocrine disorders & 1 & 1 & 2 & 1 & 23.2 \\
\hline addiction & & & & 5.8 \\
\hline Renal disease & 2 & 1 & 2 & 11.6 \\
$\begin{array}{l}\text { Gastrointestinal } \\
\text { disorders }\end{array}$ & 1 & 1 & & 23.2 \\
\hline AlDS & & 1 & & 5.8 \\
\hline leukemia & 1 & & & 5.8 \\
\hline anemia & 1 & & & 5.8 \\
\hline Orfacial pain & 1 & & & \\
\hline hepatitis & & & & \\
\hline
\end{tabular}


Table 2

The detail of Key feature examination

\begin{tabular}{|c|c|c|c|}
\hline $\begin{array}{l}\text { Number } \\
\text { of } \\
\text { questions }\end{array}$ & $\begin{array}{l}\text { Field of } \\
\text { evaluation }\end{array}$ & disease & The goal of evaluation \\
\hline 1 & $\begin{array}{l}\text { Dental } \\
\text { management }\end{array}$ & seizure & $\begin{array}{l}\text {-Student must know the dental managements of } \\
\text { convulsive patient }\end{array}$ \\
\hline \multirow[t]{4}{*}{4} & -diagnosis & \multirow{4}{*}{$\begin{array}{l}\text { Endocrinal } \\
\text { disorders }\end{array}$} & \multirow{4}{*}{$\begin{array}{l}\text { - Student must diagnose the oral signs and } \\
\text { symptoms of Addison disease and prescribe the } \\
\text { laboratory tests } \\
\text { - Student should prescribe the laboratory tests for } \\
\text { hyper thyroid patient before dental management. }\end{array}$} \\
\hline & -laboratory & & \\
\hline & & & \\
\hline & -data collection & & \\
\hline 1 & $\begin{array}{l}\text { Pretreatment } \\
\text { consideration }\end{array}$ & IV drug users & $\begin{array}{l}\text { - Student must know pretreatment consideration } \\
\text { of IV drug users }\end{array}$ \\
\hline \multirow[t]{2}{*}{2} & \multirow[t]{2}{*}{$\begin{array}{l}\text { On treatment } \\
\text { consideration }\end{array}$} & \multirow[t]{2}{*}{ Kidney } & $\begin{array}{l}\text { - Student must know pre-extraction consideration } \\
\text { of kidney transplant patients }\end{array}$ \\
\hline & & & $\begin{array}{l}\text { - student must know pretreatment consideration of } \\
\text { hemodialysis patients }\end{array}$ \\
\hline \multirow[t]{3}{*}{4} & $\begin{array}{l}\text {-Pretreatment } \\
\text { consideration }\end{array}$ & \multirow[t]{3}{*}{ gastrointestinal } & $\begin{array}{l}\text { - Student must know pre-extraction consideration } \\
\text { of inflammatory bowel disease patients }\end{array}$ \\
\hline & $\begin{array}{l}\text { - Dental } \\
\text { management }\end{array}$ & & $\begin{array}{l}\text { - Student must consider dental management of } \\
\text { patient with history of gastrectomy. }\end{array}$ \\
\hline & & & $\begin{array}{l}\text { - Student must diagnose the oral signs and } \\
\text { symptoms of Crohn disease }\end{array}$ \\
\hline 1 & -diagnosis & AIDS & $\begin{array}{l}\text { - Student must diagnose the oral signs and } \\
\text { symptoms of AIDS }\end{array}$ \\
\hline 1 & -diagnosis & leukemia & $\begin{array}{l}\text { - Student must diagnose the oral signs and } \\
\text { symptoms of leukemia. }\end{array}$ \\
\hline 1 & $\begin{array}{l}\text { Pretreatment } \\
\text { consideration }\end{array}$ & anemia & $\begin{array}{l}\text { - Student must know pretreatment consideration } \\
\text { of anemic patients. }\end{array}$ \\
\hline 1 & $\begin{array}{l}\text { Pretreatment } \\
\text { consideration }\end{array}$ & Orofacial pain & $\begin{array}{l}\text { - Student must diagnose the symptoms of } \\
\text { orofacial pain. }\end{array}$ \\
\hline 1 & $\begin{array}{l}\text { Pretreatment } \\
\text { consideration }\end{array}$ & hepatitis & $\begin{array}{l}\text { - Student must know pre-extraction consideration } \\
\text { of hepatitis. }\end{array}$ \\
\hline
\end{tabular}

In order to inform students about KF test, a pilot study was conducted to familiarize them with reasoning questions at the beginning of the semester. Students spend one-month course of oral and maxillofacial diseases. All participants participated in the study with ethical considerations provided that they want to participate in the study. Key features test scores were calculated from zero to 100. In addition to the 
instant feedback included in the questions, a face-to-face feedback session for students was scheduled and conducted the next day after test. Moreover, the students completed DTI test.

\section{Instruments:}

Satisfaction questionnaire consisted of 10 questions. (Cronbach's alpha $=0.85$ ). The scoring of questionnaire was on a 5-point Likert scale. The DTI was developed by Bourdieu et al. in France and consists of 41 questions on a 6-point Likert scale, of which 21 are memory structure category and 20 are in flexibility in thinking category. Based on this questionnaire, individuals use a tool to evaluate themselves in different situations and DTI has an acceptable validity $(a=0.83)$ that can distinguish between mastery and novice diagnosis (24). This questionnaire was psychometric in soltani-Arabshahi study in $\mathrm{X}$ context (18).

Data were analyzed using SPSS 19 by descriptive tests (mean, SD, percentage) and student independent T-test and Pearson test. Significance level was determined $p<0.05$.

\section{Data analysis}

Data were analyzed by descriptive statistics (mean and standard deviation) and analytical tests (Pearson, student t-test).

\section{Ethical consideration}

This study was approved by the Committee of Ethics in Human Research at X. (IR.SSU.REC.1399.302). In this study, an informed consent was obtained from the participants. Eligible participants were informed about the aim of the study, the method, and confidentiality of their responses by e-mail. All methods were performed in accordance with the relevant guidelines and regulations by the ethical certification. (IR.SSU.REC.1399.302).

\section{Results}

\section{Participants}

In this study, 61 dental students participated, of which 36 were male (59\%) and 25 (41\%) were female. Their mean age was $23 \pm 2.76$.

The mean scores of the key features test of students are shown in Table 3. No significant difference was reported between clinical reasoning scores of key features test by students' gender ( $p$-value $=0.19$ ). 
Table 3

Clinical reasoning score of students from $\mathrm{KF}$ test

\begin{tabular}{|c|c|c|c|}
\hline & Mean \pm Std. Deviation & Maximum & Minimum \\
\hline Clinical Reasoning Score & $56.55 \pm 7.80$ & 70.00 & 36.71 \\
\hline \multicolumn{4}{|l|}{ Gender } \\
\hline Male & $57.63 \pm 7.23$ & 70.00 & 42.71 \\
\hline Female & $55.00 \pm 8.48$ & 69.88 & 36.71 \\
\hline
\end{tabular}

The students' satisfaction scores were $3.53 \pm 0.52$ which showed relative satisfaction about the reasoning test in the oral and maxillofacial diseases course. The lowest score was 2.27 and the highest score was 4.90. There was no significant difference between the satisfaction levels of male and female participants $(p$-value $=0.12)$. DTI score in students showed in Table 4 and 5.

Table 4

Frequency of DTI score level of students

\begin{tabular}{|lll|}
\hline & Number (\%) & Score of DTI \\
\hline Very poor & $54(88.5)$ & $<150$ \\
\hline poor & $2(3.3)$ & $150-155$ \\
\hline moderate & $2(3.3)$ & $156-160$ \\
\hline good & $1(1.6)$ & $161-165$ \\
\hline Very good & $0(0)$ & $166-170$ \\
\hline excellent & $2(3.3)$ & $171-246$ \\
\hline
\end{tabular}

Table 5

Diagnostic thinking scores of students in different domains

\begin{tabular}{|llll|}
\hline & Mean \pm Std. Deviation & Maximum & Minimum \\
\hline Diagnostic thinking & $136.47 \pm 16.45$ & 175.00 & 93.00 \\
\hline Flexibility in thinking & $72.22 \pm 11.15$ & 93.00 & 45.00 \\
\hline Structure of memory & $64.24 \pm 7.84$ & 84.00 & 43.00 \\
\hline
\end{tabular}

According to Table 4, there was no significant difference between the scores of diagnostic thinking between males and females ( $p$-value $=0.11$ ). This significant difference was not reported in the domain 
of memory structure. (P-value $=0.66)$. However, the difference in students' scores in the flexibility in thinking domain was significantly higher among male students than female students. (P-value $=0.04)$. (Table 6).

Table 6

Diagnostic thinking scores of students

\begin{tabular}{|llll|}
\hline & Gender & Mean \pm Std. Deviation & p-value \\
\hline Diagnostic thinking & Male & $139.28 \pm 17.24$ & 0.11 \\
\cline { 2 - 4 } & Female & $132.44 \pm 14.64$ & \\
\hline Flexibility in thinking & Male & $74.66 \pm 10.55$ & 0.04 \\
\cline { 2 - 4 } & Female & $68.72 \pm 11.26$ & \multirow{2}{*}{0.66} \\
\hline Structure of memory & Male & $64.61 \pm 8.42$ & \\
\cline { 2 - 3 } & Female & $63.72 \pm 7.06$ & \\
\cline { 2 - 4 } & \multicolumn{2}{|l}{} & \\
\hline
\end{tabular}

The results of Pearson correlation showed that there was no significant correlation between students' diagnostic thinking scores and their clinical reasoning scores in the key features test $(r=0.16, P$-value $=$ 0.19). Accordingly, there was no significant relationship between learners' key features test scores with DTI test $(r=0.16$, P-value $=0.19)$ and DTl's domains including diagnostic thinking flexibility $(r=0.15, P$ value $=0.24)$ and memory structure $(r=0.14$, P-value $=0.32)$.

\section{Discussion}

In this study, key features test and DTI questionnaire was used to assess the clinical reasoning of senior dental students. In each clinical case, some important points were embedded that should be considered in clinical decision-making independently and in combination with other factors. The KF is a test based on an individual's clinical reasoning that solves the patient's problem step by step (25).

In the present study, the scores of KF test were at low level and no difference was observed between two genders. the scores of clinical reasoning in Zamani's study were higher than the students' scores in the present study (25). It is worthy to be mentioned that achievement of the clinical educational approach should be applied in dental schools. In the midwifery school, the students experienced an experimental cycle in education. They encountered real situations as a team member and must be manage and make decisions to solve the patient problems. It seems the experimental situation improved the clinical reasoning abilities among midwifery learners. In Zamani's study, the satisfaction of students from KF test was $2.78 \pm 0.56$ out of 5 , which did not differ significantly between strong and weak students (25). In the present study, it was $3.53 \pm 0.52$ that showed moderate satisfaction which was consistent with the results of the Branch study (26). 
In the present study, similar to the study of Arabshahi et al. the Iranian version of the DTI questionnaire was used to assess the clinical reasoning of dental students. The results of the study by Arabshahi et al. showed that the mean score of clinical reasoning of the participants was moderate and diagnostic thinking was not significantly different between residents and interns in terms of components of memory structure and flexibility in thinking. The present resultis showed the DTI scores of senior dental students were less than that among medical learners in Arabshahi's study. In terms of flexibility in thinking, the results of both studies were close to each other, but the score of memory structure was higher among medical students in the Arabshahi study (18). The result may achieve due to the investigated dental school focused on the improvement of procedural skills of learners more than the thinking abilities such as critical thinking, diagnostic thinking and reasoning skills.

It should be noted that DTI is a test based on participants' self-expression and its subjective nature can affect the results. Tajvidi et al. in 2019 showed there were direct and positive relationship between clinical reasoning and critical thinking in nurses (21). In another study, Rahayu et al. measured clinical reasoning skills in 1135 medical and general practitioners (19). The highest score of clinical reasoning in the study of Rahayu et al. was related to general practitioners (178) and year-4 students (168), respectively (19). In the present study, the scores of dental students were significantly lower than those of Rahayu et al. Rahayu et al mentioned in order for the DTI results to be reliable, it is better to participants have at least 4 years of clinical activity experience, so in the present study, senior dental students were selected (19). In 2015, Sajadi et al. compared the ability of dental students to answer multiple-choice questions and clinical reasoning and calculated their relationship to academic achievement. They concluded that despite good academic achievement, students' ability to answer the clinical reasoning test was low and they gained lower scores compared to multiple-choice tests (27).

In the present study, there was no significant difference in diagnostic thinking between males and females, which was similar to the study of Gehler et al. No significant relationship was reported in the domain of flexibility in thinking. In the study of Gehler et al., there was a significant difference between the two genders in terms of flexibility in thinking, and males scored better than females (28). This result was inconsistent with the results of Tajvidi's study, in which females scored better on clinical reasoning. Diagnostic thinking was poor among dental students in the present study, which was consistent with the results of the study by Tajvidi et al. Also, Tajvidi et al. reported clinical reasoning ability in nursing students and nurses at a moderate level (21) that their participants' scores were higher than students' score in our study. In their study, the reasoning ability of nurses was measured, while in the present study, the reasoning ability of senior dental students who did not have experience of clinical practice and service delivery as a healthcare provider. In addition, the differences of curriculum and clinical education, and the experience of participants may affect on the results. Therefore, it is recommended to conduct further study to assess the influence of experience factor on the development of reasoning skills among dental students and dentists.

Despite obtaining the mean score on the KF test, students' satisfaction about the test was moderate. Existence of structured responses is one of the reasons for increasing learners' satisfaction with this type 
of test. Most satisfied with the statement "This test allows me to understand my strengths and weaknesses in the process of diagnosis and management of oral lesions", so it can be said that the use of reasoning tests by providing immediate feedback and objective structured answers can be effective and provide better learning opportunities for students. In addition, in the present study, a face-to-face feedback session was holed to improve the educational impact of the test. Due to the low level of clinical reasoning among the participants of the present study, similar to other studies in X context, the planning for teaching and evaluating clinical reasoning in a codified way in different departments of dental schools is necessary.

One of the limitations of the present study was the small number of participants in the investigated dental school. In addition, the complexity of understanding the questions of the DTI took a lot of time for the test takers to complete the questionnaire, which can be effective in answering the final questions of the questionnaire.

\section{Conclusion}

Based on the results of the present study, clinical reasoning and diagnostic thinking skills were relatively low among dental students. This issue emphasizes the need for training to enhance diagnostic thinking and reasoning capabilities in dental education. In order to improve this skill in dental students, there is a need to reform the educational programs of this course. It is recommended that clinical reasoning tests be considered formatively to assess the clinical skills of these students.

\section{Declarations}

\section{Acknowledgements:}

This project was funded by the National Agency for Strategic Research in Medical Education, Tehran, Iran. Grant No.981612.

\section{Authors' contributions:}

F.O. \& F.K. conceptualized and designed the study. F.O. \& M.K. \& F.RM. collected the data. F.K. analyzed the data. F.O. and F.K. wrote the main manuscript text. All authors have met criteria for authorship and had a role in preparing the manuscript. Also, all authors approved the final manuscript.

\section{Funding}

This study was supported by a grant from the National Center for Strategic Research in Medical Education (NASR) in Ministry of Health and Medical Education (No.981612) Tehran, Iran. The grant supported data collection process. The funders had no role in the design of the study and collection, and analysis, interpretation of data or preparation of the manuscript. The report of the study's findings is sent by the authors to funder at the end of the study. 
Availability of data and materials

The datasets used and/or analyzed during the current study are available from the corresponding author on reasonable request.

\section{Ethics approval and consent to participate}

This study was approved by the Committee of Ethics in Human Research at X. (IR.SSU.REC.1399.302). In this study, an informed consent was obtained from the participants. Eligible participants were informed about the aim of the study, the method, and confidentiality of their responses by e-mail. All methods were performed in accordance with the relevant guidelines and regulations by the ethical certification. (IR.SSU.REC.1399.302).

\section{Consent for publication}

Not Applicable.

\section{Competing interests}

The authors declare that they have no competing interests.

\section{References}

1. Banning, M. Clinical reasoning and its application to nursing: Concepts and research studies. Nurse Education in Practice, 8 (3), 177-183 (2008).

2. Norman, G. Research in clinical reasoning: past history and current trends. Medical education, 39 (4), 418-427 (2005).

3. Gruppen, L. D. Clinical Reasoning: Defining It, Teaching It, Assessing It, Studying It. The western journal of emergency medicine, 18 (1), 4-7 (2017).

4. Hsu, T-C. et al. Core clinical competencies for dental graduates in Taiwan: Considering local and cultural issues. Journal of Dental Sciences, 10 (2), 161-166 (2015).

5. Frank, J. R. et al. Competency-based medical education: theory to practice. Medical teacher, 32 (8), 638-645 (2010).

6. Levin, M., Cennimo, D., Chen, S. \& Lamba, S. Teaching Clinical Reasoning to Medical Students: A Case-Based Illness Script Worksheet Approach. MedEdPORTAL: the journal of teaching and learning resources, 12, 10445 (2016).

7. del Bueno, D. A crisis in critical thinking. Nursing education perspectives, 26 (5), 278-282 (2005).

8. Simmons, B. Clinical reasoning: concept analysis. Journal of advanced nursing, 66 (5), 1151-1158 (2010).

9. Killam, L. A., Luhanga, F. \& Bakker, D. Characteristics of unsafe undergraduate nursing students in clinical practice: an integrative literature review. The Journal of nursing education, 50 (8), 437-446 
(2011).

10. Tanner, C. A. Thinking like a nurse: a research-based model of clinical judgment in nursing. The Journal of nursing education, 45 (6), 204-211 (2006).

11. Gerhard-Szep, S. et al. Assessment formats in dental medicine: An overview. GMS journal for medical education, 33 (4), Doc65 (2016).

12. Safi, Y. et al. Designing and Implementation of a Course on Successful Dental Practice for Dentists. Journal of dentistry (Tehran, Iran), 12 (6), 447-455 (2015).

13. Levett-Jones, T. et al. The 'five rights' of clinical reasoning: An educational model to enhance nursing students' ability to identify and manage clinically 'at risk'patients. Nurse education today, $\mathbf{3 0}$ (6), 515-520 (2010).

14. Nikendei, C. et al. Effects of a supplementary final year curriculum on students' clinical reasoning skills as assessed by key-feature examination. Medical teacher, 31 (9), e438-42 (2009).

15. Amini, M., Moghaddami, M., Lotfi, F., Kazempour, R. \& Abdolfathi, E. Comparison between key feature exam and multiple choice questions in internal medicine department of Shiraz University of medical sciences. Hormozgan Med J, 17 (3), e88180 (2013).

16. Huwendiek, S. et al. Electronic assessment of clinical reasoning in clerkships: A mixed-methods comparison of long-menu key-feature problems with context-rich single best answer questions. Medical teacher, 39 (5), 476-485 (2017).

17. Nayer, M., Glover Takahashi, S. \& Hrynchak, P. Twelve tips for developing key-feature questions (KFQ) for effective assessment of clinical reasoning. Medical teacher, 40 (11), 1116-1122 (2018).

18. SK, S. A., Monajemi, A., Kuhpayehzadeh, J., Gholami, T. \& Khajavi, M. Evaluation of clinical reasoning of interns and residents of Iran University of Medical Sciences, 2013. RJMS, 22 (132), 19-25 (2015).

19. Rahayu, G. R. \& McAleer, S. Clinical reasoning of Indonesian medical students as measured by diagnostic thinking inventory. South East Asian journal of medical education, 2 (1), 42-47 (2008).

20. Groves, M., O'Rourke, P. \& Alexander, H. The clinical reasoning characteristics of diagnostic experts. Medical teacher, 25, 308-313 (2003).

21. Tajvidi, M. moghimi,soheila. The Relationship Between Critical Thinking and Clinical Competence in Nurses. Strides in Development of Medical Education, 16 (1), 0-0 (2019).

22. Orujlu, S. \& Hemmati Maslakpak, M. Assessing the relationship between critical thinking and selfefficacy of nursing student. Journal of Nursing Education, 5 (6), 11-17 (2017).

23. Hamzeh, H., Madi, M. \& Hensman, M. The Use of Diagnostic Thinking Inventory to Evaluate Musculoskeletal Physiotherapy Practitioners' Clinical Reasoning2016.

24. Bordage, G., Grant, J. \& Marsden, P. Quantitative assessment of diagnostic ability. Medical education, 24 (5), 413-425 (1990).

25. Zamani, S. et al. The comparison of the key feature of clinical reasoning and multiple choice examinations in clinical decision makings ability. Biomed. Res, 28 (3), 1115-1119 (2017). 
26. Branch, C. An assessment of students' performance and satisfaction with an OSCE early in an undergraduate pharmacy curriculum.Currents in Pharmacy Teaching and Learning. 2013;6.

27. Sajadi, F. S. Research Article Comparison of Dental Students' Ability to Answer PMP-MEQ and MCQTests and Its Association with Educational Progress.

28. Gehlhar, K., Klimke-Jung, K., Stosch, C. \& Fischer, M. R. Do different medical curricula influence selfassessed clinical thinking of students? GMS Zeitschrift fur medizinische Ausbildung. 2014;31(2):Doc23. 